\title{
To assess the adherence to antiretroviral therapy among HIV positive patients attending ART centres in Haryana and its effect on their quality of life
} Arundeep Singh ${ }^{1}$, Anshu Mittal ${ }^{2}$, Vishavdeep Kaur ${ }^{3}$

${ }^{1}$ Department of Community Medicine, Maharishi Markandeshwar Institute of Medical Sciences and Research, Mullana, Ambala, Haryana, India; ${ }^{2}$ Prof. \& Head, Department of Community Medicine, Maharishi Markandeshwar Institute of Medical Sciences and Research, Mullana, Ambala, Haryana, India; ${ }^{3}$ Professor, Department of Physiology, Maharishi Markandeshwar Medical College \& Hospital, Kumarhatti, Solan, Himachal Pradesh, India

\begin{tabular}{|c|c|c|c|c|c|c|c|}
\hline Abstract & Introduction & Methodology & Results & Conclusion & References & Citation & Tables/ Figures \\
\hline
\end{tabular}

\section{Corresponding Author}

Dr Anshu Mittal, Prof. \& Head, Department of Community Medicine, Maharishi Markandeshwar Institute of Medical Sciences \& Research, Mullana, Ambala (Haryana), India

E Mail ID: $\underline{\text { dr.anshumittal@mmumullana.org }}$

\section{Citation}

Singh A, Mittal A, Kaur V. To assess the adherence to antiretroviral therapy among HIV positive patients attending ART centres in Haryana and its effect on their quality of life. Indian J Comm Health. 2021;33(2):314-318. https://doi.org/10.47203/IJCH.2021.v33i02.016

Source of Funding: Nil Conflict of Interest: None declared

\section{Article Cycle}

Received: 16/02/2021; Revision: 11/04/2021; Accepted: 05/06/2021; Published: 30/06/2021

This work is licensed under a Creative Commons Attribution 4.0 International License.

\section{Abstract}

Background: Acquired immune deficiency syndrome (AIDS) is now considered as a manageable chronic illness with the availability of ART. A high level of adherence ( $>95 \%)$ is required for antiretroviral therapy to be effective. It is a syndrome that builds a vacuum in a person affecting his/her quality of life (QOL) as a whole. Aim\& Objective: The aim of our study was to determine adherence and its effect on their quality of life among HIV/AIDS patients attending FIART (Facility Integrated Antiretroviral therapy) clinic. Materials and Methods: Using a cross-sectional study design, 257 HIV positive patients receiving antiretroviral therapy at Facility integrated anti-retroviral therapy centre Ambala Haryana. QOL of patients taking ART was assessed using WHO-QOL-BREF questionnaire. Results: Of 257 participants, $88.3 \%$ were found to be adherent, adherent to ART therapy and ambulatory had better QOL $(p<0.05)$ than their counterparts from other socio-clinical strata. Mean scores of physical (70.89 \pm 7.384$)$, psychological $(47.37 \pm 9.174)$, social $(51.97 \pm 11.119)$ \& environmental domains $(52.33 \pm 9.081)$, were having highest in patients those who were adherent (adherence rate $>95 \%$ ) to ART therapy. Conclusion: Adherence to antiretroviral therapy in Haryana India is suboptimal. Intensive adherence counselling should be provided to all patients before initiation of antiretroviral therapy and on every visit to FIART centre.

\section{Keywords}

Quality of Life (QOL); Anti-Retroviral Therapy (ART); AIDS; HIV; Facility Integrated ART centre (FIART); Patient Living with HIV/AIDS (PLHIV/AIDS)

\section{Introduction}

AIDS has a chronic debilitating course and the long-term adverse effects of current treatment modalities are uncertain. The social stigma attached with HIV may at times force the individual to change the job or the place of living which may put further stress on the already weak economic situation. .(1)

The extensive use of ART has resulted in it being managed; available evidence supports the benefits of ART in improving HRQOL outcomes and life expectancy of those infected with HIV and hence achieving good ART adherence is central for long-term outcomes in PLWH. (2)
Quality of life is a term that is popularly used to convey an overall sense of well-being and includes aspects such as happiness and satisfaction with life as a whole. According to the World Health Organization,(3) Quality of life (QOL) is defined as individuals' perceptions of their position in life in the context of the culture and value systems in which they live and in relation to their goals, expectations, standards and concerns.

In this context, the quality of life of people living with HIV/AIDS and its relationship with ART become an objective of study. Many studies assess the QoL of these people; however, those addressing the relationship between QoL and ART are rare. 


\section{Aim \& Objective}

To determine how adherence or non-adherence is affecting the quality of life in the people living with HIV/AIDS.

\section{Material \& Methods}

This was a cross-sectional study and was conducted at ART Centre Ambala of Haryana. Which was now upgraded as FIART (Facility Integrated Anti-Retroviral Therapy) centre. Study subjects: The study population included HIV/AIDS sero-positive patients registered at FIART centres receiving Anti-Retroviral Therapy who fulfil the inclusion criteria.

Inclusion criteria: HIV/AIDS positive patients more than 18 years of age, Patients who were registered for more than 6 months/, HIV/AIDS positive patients who gave consent. Exclusion criteria: HIV positive patients who were not in a condition to give information.

Study period: The study was carried out over a period of one year i.e., January 2019 to December 2019.

Sample size: Sample size was estimated on the basis of $81.4 \%$ of adherence of ART reported in a study by Bharatesh D. Basti et al (2017)(4). Sample size was estimated to be around 233 subjects at .05 absolute error and after adding $10 \%$ non-response rate, the final sample size came out to be 257 subjects.

Study tools: Adherence to ART therapy were calculated by using Medication AdherenceScale. The nine question Medication Adherence Scale (MAS) is a self-reported questionnaire to assess medication adherence. The scale consists of nine questions, first eight items having a dichotomous answer (yes/no) that indicates adherence or non-adherent behaviour. For question no. 9, a patient can choose an answer on 5 -point likert scale, expressing how often happens that a patient does not take his medication. MAS scores can range from 1 to 13 points. Scores $>11$ indicates adherence (>95\%)(5) to medication.

Quality of life was evaluated using the World Health Organization Quality of life (WHOQOL)(6) Brief instrument,7The WHOQOL Brief consists of 26 items. Each item uses a Likert-type five-point scale. These items are distributed in four domains. The four domains of QOL are,

a) Physical health and level of independence (seven items assessing areas such as presence of pain and discomfort; dependence on substances or treatments; energy and fatigue; mobility; sleep and rest; activities of daily living; perceived working capacity);

b) Psychological well-being (eight items assessing areas such as Affect, both positive and negative selfconcept, higher cognitive functions; body image and spirituality),

c) Social relationships (three items assessing areas such as social contacts, family support and ability to look after family; sexual activity) d) Environment (eight items assessing areas such as freedom; quality of home environment; physical safety and security and financial status; involvement in recreational activity; health and social care: quality and accessibility).

There are also two items that are examined separately: one which asks about the individual's overall perception of QOL and the other which asked about the individual's overall perception of his or her health. Domain scores are scaled in a positive direction (Higher scores denote higher quality of life). The scores thus obtained were added for each domain and further transformed to a new score which ranged from 0 (minimum) to 100 (maximum), with a higher score indicating better quality of life, for every domain separately.

Statistical Analysis: The data was entered in excel sheet and analyzed using Statistical Product and Service Solutions (SPSS) version 20.0.

Qualitative variables will be expressed as proportions in percentages.

Quantitative variables i.e., Quality of life scores score will be expressed as mean and standard deviation.

Finally, Chi-square test was used to establish association (if any) among qualitative variables.

Association between the various quantitative variables was established using t-test or ANOVA as per requirement of data.

$P<0.05$ was considered significant at $95 \%$ confidence interval.

Ethical Consideration: A prior approval from The Institutional Ethics committee was obtained. The study was submitted for approval to the Institutional Ethics Committee. The study did not impose any financial burden on the patients. Written informed consent was obtained from each participant in their vernacular language. Confidentiality for each patient was maintained throughout the study.

\section{Results}

(Table 1) shows Sociodemographic characteristics and clinical information of patients that out of total 257 patients with mean age of $38.46 \pm 11.077$ years; ranged from 18 to 62 years were included in the final analysis. Males comprised 144 (56\%) of participants. Majority of the patients $91(35.4 \%)$ completed primary education and $183(71.2 \%)$ patients were married. Most of the participants 168 (65.4\%) belong to upper class of modified BG Prasad socioeconomic scale. Mostly 115 (44.7\%) of participants were unemployed. Most of the participants $109(42.4 \%)$ had a normal BMI. Only $14(5.7 \%)$ of patients had CD4 count $<250$ cells $/ \mathrm{mm} 3$ and 176 (68.5\%) of them had CD4 count $>500$ cells $/ \mathrm{mm} 3$

(Figure 1) shows that Adherence to HAART was assessed using the nine question Medication Adherence Scale (MAS). MAS scores can range from 1 to 13 points. Scores $>11$ indicates adherence (> 95\%) to medication. 
Accordingly, out of 257 patients, 227 (88.3\%) patients were adherent to HAART (corresponding to adherence rate $>95 \%)$,

(Table 2) shows that all the domains physical (70.89 \pm 7.384$)$, psychological $(47.37 \pm 9.174)$, social (51.97 \pm 11.119$)$ \& environmental $(52.33 \pm 9.081)$, were having highest mean scores in patients those who were adherent (adherence rate $>95 \%$ ) to ART therapy. The difference was also highly significant statistically in physical domain, no statistical significance was seen in psychological, social \& environmental domain. All the domains had lowest mean score in those PLHIV who were not adherent (adherence rate $<95 \%$ ) to ART therapy.

\section{Discussion}

In our study the mean age of patients was $38.46 \pm 11.077$ years. $56 \%$ patients were female, $42.8 \%$ patients were male. Similarly, in another study by Peter, Emanuel et al. (2014), found that $52.7 \%$ were females and $47.3 \%$ were males.(7) In our study $49 \%$ (126) were from the rural area and $51 \%$ were from the urban area. Similarly, study conducted by Mehta KG, Baxi R, Patel S, Parmar M. (2016) also reported that $50.56 \%$ patients were belong to rural area and $49.43 \%$ patients were belong to urban area, which shows equal distribution of patients in both areas. Patients in the study group indicate that both urban and rural population have equal risk of having HIV infection(8). The present study showed that majority of patients i.e., $71.2 \%$ (183) were married. Similar participants were seen in the study done by Mehta KG, Baxi R, Patel S, Parmar M. (2016) in western India, $68.91 \%$ of the study subjects were married. The current study showed that maximum patients i.e., $35.4 \%$ (91) was educated up to primary standard Similar study done by Vigneshwaran et al. (2013) in Andhra Pradesh found that $34.2 \%$ had primary level education(9). In the present study, maximum number of patients i.e., 44.7\% (115) were unemployed. In our study according to modified BG Prasad scale, maximum number of patients i.e., $65.4 \%$ (168) belong to upper class. In other study conducted by Gowda S, Channabasappa AN, Dhar M, Krishna D (2014) in Mysore showed that majority of patients belonged to middle income group (43.5) in class II and $29.0 \%$ in class III.(10) In present study CD4 count for the maximum number of patients $68.5 \%$ (176) were $>500$. $26.1 \%$ (67) patients were in the range of 200-500. Minimum number of patients i.e., 5.7\% (14) were having CD4 count <200. Anand, Deepika et al. (2012) found in their study conducted in New Delhi, that 38.6\% patients have CD4 count $<200,45.1 \%$ have CD4 counts between 200-500, while $16.3 \%$ patients have CD4 count $>500 .(11)$ The difference could be attributed to the fact that ART is now being offered to all HIV positive patients from beginning helping to decrease viral load and hence better CD4 counts.

The present study, was based upon Nine-point Medication Adherence Scale with scores ranging from 1 to 13, A Score of $>11$ suggest that patients is Adherent with Adherence rate $>95 \%$ and $\leq 11$ suggest that the patient was NonAdherent with Adherence rate $<95 \%$. Out of the total patients, $88.3 \%$ (227) were adherent to ART therapy, $11.7 \%$ (30) patients Non-Adherent to ART therapy. Similar study results were seen in study conducted by Gokarn A. et al. (2012) on 300 patients attending ART centre for more than 6 months to see adherence to ART therapy found that on MAS scale $78 \%$ of the patients were found Adherent to treatment with adherence rate > 95\%.5 Another study done by Alvi Yasir et al. (2019) at ART centre, Aligarh also showed that prevalence of adherence was $81.3 \% .(12)$ In current study adherence to antiretroviral treatment in the ART centre is comparatively high which may be due to dedicated and competent healthcare providers in the region.

In current study all the domains were having highest mean scores in patients those who were adherent (adherence rate $>95 \%$ ) to ART therapy. The difference was also highly significant statistically in physical domain $(P=<0.001)$. In study conducted by e Silva AC et al. (2014)13 found similar results that the individuals classified as "non-adherent" presented the worst scores in all the QOL domains and presented statistically significant results for physical, psychological and social domains(13). The relationship between adherence to ART and quality of life is reciprocal. Even in the latest study done by Yaya I et al. (2019) also found that adherence is significantly associated with adherence to ART $(p<0.0001)$.(14)

\section{Conclusion}

It was observed that the QOL scores were better among those people who were adherent to ART. Thus, we can conclude that adherence to ART improves the QOL among PLHIV/AIDS. Regular counselling and generating awareness regarding regularity of obtaining treatment will increase the patient's adherence and hence their QOL.

\section{Recommendation}

Regularity of ART among PLHIV/ AIDS must be ensured by the patients themselves and the health care providers must support them in every possible way to maintain higher levels of adherence like having regular meetings among patients, psychosocial support with the help of family and other community leaders.

\section{Limitation of the study}

It was facility based study hence the adherence although not upto the mark but still may be higher than actual levels, latter can be highlighted in community based studies which could have provided some evidence regarding role of community support and involvement to improvise on adherence.

\section{Relevance of the study}

The study has highlighted the role of maintaining higher levels of adherence which are required to have better quality of life of PLHIV/ AIDS, specifically in this part of 
country and thus will be able to help the policymakers, healthcare providers and other stakeholders to device solutions to achieve the best.

\section{Authors Contribution}

AS: Conception and design of the work; Data Collection, analysis, and interpretation of data for the work, preparing the final draft. AM: Conception and design of the work, interpretation of data for the work, Final approval of the version to be published. VK: Drafting the work and revising it critically for important intellectual content

\section{Acknowledgement}

District Health authorities for giving us the permission to contact the patients reporting at FIART clinic.

\section{References}

1. Wig N, Lekshmi R, Pal H, Ahuja V, Mittal CM, Agarwal SK. The impact of HIV/AIDS on the quality of life: a cross sectional study in north India. Indian J Med Sci. 2006;60(1):3-12.

2. Aranda-Naranjo B. Quality of life in the HIV-positive patient: implications and consequences. I Assoc Nurses AIDS Care. 2004;15(5 Suppl):20S-27S.

3. The World Health Organization Quality Of Life (WHOQOL) -Bref Available from http://www.who.int/substance abuse/research tools/en/english whogol.pdf. (last assessed on 25/06/2021)

4. Mahesh V, Basti B, Bant D et al. Factors affecting antiretroviral treatment adherence among people living with human immunodeficiency virus/acquired immunodeficiency syndrome: A prospective study. Journal of Family Medicine and Primary Care. 2017;6(3):482-6

\section{6.} antiretroviral therapy. J Assoc Physicians India. 2012;60:16-20.

WHO. Healthy at Home-Mental Health. Geneva: WHO 2020. Available from: https://www.who.int/mental_health/media/en/76.pdf?ua=1 (Last assessed on 25.06.2021)

7. Peter E, Kamath R, Andrews T et al. Psychosocial Determinants of Health-Related Quality of Life of People Living with HIV/AIDS on Antiretroviral Therapy at Udupi District, Southern India. Int J Prev Med. 2014;5(2):203-209.

8. Mehta K, Baxi R, Patel S et al. Drug adherence rate and loss to follow-up among people living with HIV/AIDS attending an ART Centre in a Tertiary Government Hospital in Western India. Journal of Family Medicine and Primary Care. 2016;5(2):266-269.

9. Vigneshwaran E, Padmanabhareddy $Y$, Devanna N et al. Gender differences in health-related quality of life of people living with HIV/AIDS in the era of highly active antiretroviral therapy. North Am J Med Sci 2013; 5:102-7.

10. Gowda S, Channabasappa AN, Dhar M et al. Quality of life in HIV/AIDS patients in relation to CD4 count: A cross-sectional study in Mysore district. Int J Health Allied Sci. 2012; 1:263-7.

11. Anand D, Puri S, Mathew M. Assessment of Quality of Life of HIVPositive People Receiving ART: An Indian Perspective. Indian J Community Med.2012;37(3):165-169.

12. Alvi $\mathrm{Y}$, Khalique $\mathrm{N}$, Ahmad A et al. World Health Organization Dimensions of Adherence to Antiretroviral Therapy: A Study at Antiretroviral Therapy Centre, Aligarh. Indian J Community Med. 2019;44(2):118-124.

13. Ana Cristina De Oliveira E Silva, Reis RK, Nogueira JA et al. Quality of life, clinical characteristics and treatment adherence of people living with HIV/AIDS. Revista Latino-Americana de Enfermagem. 2014;22(6):994-1000.

14. Yaya, I., Djalogue, L., Patassi, A.A. et al. Health-related quality of life among people living with HIV/AIDS in Togo: individuals and contextual effects. BMC Res Notes12,140 (2019).

\section{Tables}

\begin{tabular}{|c|c|c|c|}
\hline & Characteristics & Total $N=257$ & Percentage $100 \%$ \\
\hline \multirow[t]{3}{*}{ Gender } & Male & 144 & 56 \\
\hline & Female & 110 & 42.8 \\
\hline & Transgender & 3 & 1.2 \\
\hline \multirow{4}{*}{ Age Groups/ Years } & $<25$ & 31 & 12.1 \\
\hline & $25-35$ & 82 & 31.9 \\
\hline & $36-45$ & 99 & 38.5 \\
\hline & $>45$ & 45 & 17.5 \\
\hline \multirow{2}{*}{ Residence Location } & Rural & 126 & 49 \\
\hline & Urban & 131 & 51 \\
\hline \multirow{4}{*}{ Marital Status } & Never Married & 33 & 12.8 \\
\hline & Married & 183 & 71.2 \\
\hline & Separated/Divorced & 8 & 3.1 \\
\hline & Widow/Widower & 33 & 12.8 \\
\hline \multirow{6}{*}{ Educational Level } & No Formal Education & 59 & 23 \\
\hline & Primary School & 91 & 55.4 \\
\hline & High School & 56 & 21.8 \\
\hline & Senior Secondary School & 34 & 13.2 \\
\hline & Graduate & 12 & 4.7 \\
\hline & Above Graduate & 5 & 1.9 \\
\hline \multirow{3}{*}{ Employment Status } & Unemployed & 115 & 44.7 \\
\hline & Govt. Job & 8 & 3.1 \\
\hline & Private Job & 57 & 22.2 \\
\hline
\end{tabular}




\begin{tabular}{|c|c|c|c|}
\hline & Characteristics & Total $N=257$ & Percentage $100 \%$ \\
\hline & Own Business & 38 & 14.8 \\
\hline & Daily Wagers & 39 & 15.2 \\
\hline \multirow{3}{*}{ Type of Family } & Nuclear & 183 & 71.2 \\
\hline & Joint & 57 & 22.2 \\
\hline & $3^{\text {rd }}$ Generation & 17 & 6.6 \\
\hline \multirow{5}{*}{ Socioeconomic Status } & I-Upper Class & 168 & 65.4 \\
\hline & II-Upper Middle Class & 66 & 25.7 \\
\hline & III-Middle Class & 18 & 7 \\
\hline & IV-Lower Middle Class & 4 & 1.6 \\
\hline & V-Lower Class & 1 & .4 \\
\hline \multirow{3}{*}{ CD-4 Cell Count (Cells/mm3) } & $<200$ & 14 & 5.7 \\
\hline & $200-500$ & 67 & 26.1 \\
\hline & $>500$ & 176 & 68.5 \\
\hline \multirow{4}{*}{ BMI Status (KG/m2) } & $<18.5$ & 72 & 28 \\
\hline & $18.5-22.9$ & 109 & 42.4 \\
\hline & $23-24.9$ & 30 & 11.7 \\
\hline & $>25$ & 46 & 17.9 \\
\hline \multirow{4}{*}{ Time Since HIV Diagnosis (Months) } & $\leq 12$ & 70 & 27.2 \\
\hline & $13-36$ & 58 & 22.6 \\
\hline & $37-60$ & 49 & 19.1 \\
\hline & $\geq 61$ & 80 & 31.1 \\
\hline
\end{tabular}

\section{TABLE 2 QUALITY OF LIFE SCORES IN DIFFERENT DOMAINS AS PER PARTICIPANT'S ADHERENCE TO ART}

\begin{tabular}{|c|cccc|c|}
\hline Type of Adherence & Physical & Psychological & Social & Environmental \\
\hline Adherent & $70.89 \pm 7.384$ & $47.37 \pm 9.174$ & $51.97 \pm 11.119$ & $52.33 \pm 9.081$ \\
\hline Non-Adherent & $64.93 \pm 10.279$ & $45.50 \pm 8.649$ & $48.13 \pm 10.954$ & $50.87 \pm 9.247$ \\
\hline Total & $70.19 \pm 7.986$ & $47.15 \pm 9.117$ & $51.53 \pm 11.147$ & $52.16 \pm 9.095$ \\
\hline P. Value & $<0.001$ & 0.293 & 0.076 & 0.408 \\
\hline
\end{tabular}

\section{Figures}

FIGURE 1 DISTRIBUTION OF PATIENTS BY ADHERENCE (THE NINE QUESTION MEDICATION ADHERENCE SCALE WITH SCORE RANGING FROM 1 TO 13)

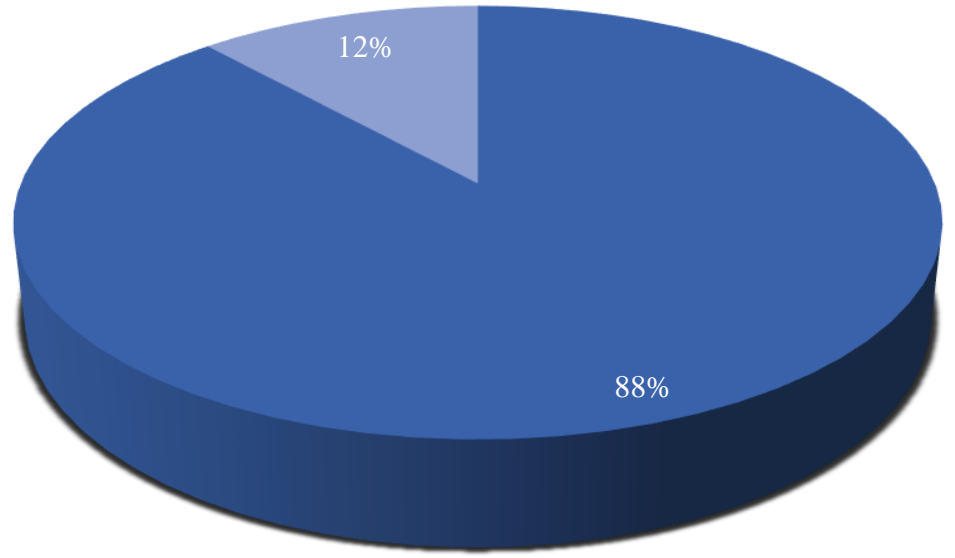

Adherent (>11) $\square$ Non-Adherent $(\leq 11)$ 